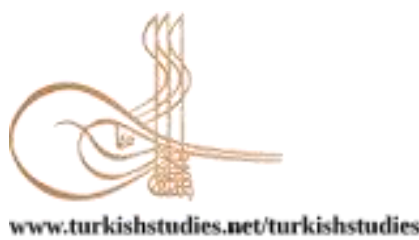

Turkish Studies

www.turkishstudies.net/turkishstudies

eISSN: $1308-2140$

BALAKAN

Sponsored by IBU

Research Article / Araștırma Makalesi

\title{
Adölesan Sporcularda Somatotip Yapı ile Sprint Yüzme Performansı Arasındaki İlişkinin İncelenmesi
}

\author{
Investigation of Correlation between Somatotype Structure and Sprint Swimming Performance in \\ Adolescent Athletes
}

\author{
Ercüment Erdoğan*
}

\begin{abstract}
The aim of this study was to determine the effect of adolescent swimmers' age, gender, and physical characteristics on their swimming performance and the correlation between their somatotype structure and four different style short distance $(50 \mathrm{~m}$.) sprint swimming performance. The sample consisted of 61 ( $\mathrm{n}=36$ females, age $=13.00 \pm 1.29$ years $)$ and $(n=25$ males, age $=13.00 \pm 1.13$ years $)$ active and healthy competitive athletes in Ordu and Giresun clubs. Participation was voluntary. Anthropometric measurements (circumference, diameter, length, and skinfold thickness) were performed using Heath \& Carter method, and the correlation between participants' somatotype structures and four different styles of short-distance sprint swimming performance was determined. Participants had a mean endomorph-mesomorph- ectomorph (somatotype) value of 3.66, 4.15, and 2.56, respectively. Female and male participants had a mean somatotype value of 3.48-4.262.82 and 3.01-4.39-2.89, respectively, indicating that they had an endomorphic mesomorphic structure. Female and male participants' somatotype structures and swimming performance were similar. Endomorphic structure was positively correlated with free $(r=242)$, backstroke $(r=254)$, butterfly $(r=269)$, and breaststroke $(r=400)$ style swimming performance. Age had a significant effect on height $(\mathrm{p}=.000)$, weight $(\mathrm{p}=.000)$, BMI $(\mathrm{p}=$ $.003)$, and free $(p=.006)$, butterfly $(p=.003)$, and breaststroke style values $(p=.030)$. There was no significant difference in somatotype structures and swimming performance between female and male participants. In conclusion, while adolescent swimmers have similar somatotype structures and performance values, the older they are, the higher swimming performance they have. There is a significant relationship between endomorphy structure and short-distance sprint swimming performance.
\end{abstract}

Structured Abstract: Swimming performance depends on certain parameters. Hand size plays a key role in swimming at a fast speed while body weight plays a key role in staying on the top of the water when swimming (Cicchella et al., 2009: 155).

Identifying the somatotype in children helps both to discover the talents and to determine the effect of loads on anthropometric structure and performance. Numerous studies focus on height, body mass index, and upper extremity (forearm and hand structure) in swimmers (Smith 1978; Sharp et al., 1982; Toussaint \& Beek, 1992; Deschodt et al., 1999; Olmez et al., 2017). Unlike those studies, determining the effect of swimming styles, somatotype characteristics, and body structure on swimming performance can allow us to focus on

\footnotetext{
${ }^{*}$ Dr. Öğr. Üyesi, Ordu Üniversitesi, Beden Eğitimi ve Spor Yüksekokulu, Beden Eğitimi ve Spor Eğitimi Bölümü. Assistant Professor, Ordu University, School of Physical Education and Sports, Department of Physical Education And Sports Teaching

ORCID 0000-0002-4544-2211

ercumenterdogan22@hotmail.com

Cite as/ Atıf: Ercüment, E. (2020). Adölesan sporcularda somatotip yap1 ile sprint yüzme performans1 arasındaki ilişkinin incelenmesi. Turkish Studies, 15(3), 1809-1820. https://dx.doi.org/10.29228/TurkishStudies.42902

Received/Geliş: 15 April/Nisan 2020

Accepted/Kabul: 20 June/Haziran 2020

Checked by plagiarism software

Copyright $($ ) MDE, Turkey

Published/Yayın: 25 June/Haziran 2020

CC BY-NC 4.0
} 
helping children develop their body according to the needs of competitions or events at an early age. The aim of this study was, therefore, to investigate the effect of age, gender, and physical characteristics on swimming performance in adolescent swimmers and the relationship between somatotype structure and four different styles short distance $(50 \mathrm{~m}$.) sprint performance.

Sample was recruited from different clubs in the city center of Ordu and Giresun. The sample consisted of 61 healthy swimmers ( 36 women $13.00 \pm 1.29$ years of age and 25 men $13.00 \pm 1.13$ years of age) who are actively engaged in sports and participate in national competitions.

Body length was measured to the nearest 0.01 using a stadiometer (Holtain Ltd., UK). Body weight was measured using a bioimpedance analyzer (ioi-353, Jawon Medical, Korea). Limb length and diameter were measured using an anthropometer (Lafayette Instrument Company). Skinfold thickness was measured using a skinfold caliper (Holtain Ltd., UK). Circumference was measured using a steel meter. Upper arm circumference $(\mathrm{cm})$, maximal leg circumference $(\mathrm{cm})$, femur diameter $(\mathrm{cm})$, humerus diameter $(\mathrm{cm})$, triceps skinfold $(\mathrm{mm})$, subscapular skinfold $(\mathrm{mm})$, supraspinale skinfold $(\mathrm{mm})$, and medial calf skinfold $(\mathrm{mm})$ were measured from the right side of the body. Somatotype was assessed using the Heath \& Carter method (Carter and Heath, 1990: 352; Mac Dougall et al., 1991: 142).

Data were analyzed using the Statistical Package for Social Sciences (SPSS) at a significance level of .05. Data were tested for normality. Descriptive statistics, Mann Whitney U test, Kruskal Wallis test and Spearman's correlation tests were used for analysis.

Participants had a mean somatotype value of 3.66-4.15-2.56. Female and male participants had a mean somatotype value of 3.48-4,26-2.82 and 3.01-4.39-2.89, respectively. Both men and women had the mesomorph somatotype. The somatotype result was consistent with the literature.

There was no significant difference in swimming performance and somatotype structures between male and female participants. Male participants outperformed female participants in all four types of swimming. Male participants had higher mesomorphy and ectomorphy values and lower endomorphy values than female participants.

There was a significant difference in height, weight, BMI, and freestyle stroke, butterfly stroke, and breast stroke values between age groups. The multiple comparison test results showed significant differences in height and weight between all age groups and a significant difference in BMI values between the 14-15 age group and the 10-11 and 12-13 age groups. These results indicate that age has an effect on physical characteristics during this period. The 14-15 age group was significantly better at freestyle swimming than the other age groups. All age groups had similar performance in butterfly stroke. The 14-15 age group was significantly better at breaststroke style swimming than the 10-11 age group.

Age was moderately and negatively correlated with butterfly and breast stroke swimming performance. Body length was moderately and negatively correlated with all four styles of swimming performance. Body weight was moderately and negatively correlated with butterfly and freestyle stroke swimming performance. These results show that age, height, and increase in weight significantly reduce the duration of swimming 50 meters, and therefore, have a positive effect on swimming performance. The results showed that swimming performance was positively correlated with the somatotype structure and that the endomorph values were moderately and positively correlated with four styles of swimming performance. There was a low and positive correlation between the mesomorph values and the backstroke, butterfly and breaststroke swimming performance. There was a low and negative correlation between the ectomorph value and the backstroke, butterfly, and breaststroke swimming performance.

Our results and those of other studies indicate that short distance swimming performance is partially accounted for by anthropometric characteristics in adolescent swimmers. Swimming performance depends on anthropometric characteristics and physical capacity as well as age, exercise level, and swimming style.

We think that the differences in swimming performance among our participants were due to their age, exercise level, and structural characteristics in the development period. Female and male participants had similar somatotype characteristics and performance because they were of similar age. Future studies should focus on different age groups (adults, masters etc.) and performance levels (club, national team etc.) to provide more insight into this matter. 
Keywords: Adolescent, Swimming, Somatotype, Sprint performance. Swimming styles.

Öz: Bu çalışmanın amacı adölesan dönem yüzme sporcularının, yaş, cinsiyet ve fiziksel özelliklerin yüzme performansına etkisinin ve somatotip yapı ile dört farklı stil kısa mesafe(50m.) sprint performansları arasındaki ilişskinin incelenmesidir. Çalışma Ordu ve Giresun il merkezinde farklı kulüplerde aktif spor yapan ve müsabık sağl1klı kadın $(n=36$, yaş $=13,00 \pm 1,29$ y1l) ve erkek $(n=25$, yaş=13,00 $\pm 1,13$ yıl) toplam 61 gönüllü sporcu üzerinde yapılmıştır. Sporcuların antropometrik ölçümleri (çevre, çap, uzunluk ve deri kıvrım kalınlığı) yapılarak Heath \&Caerter metodu ile somatotip yapıları belirlenmiş ve dört farklı stil kısa mesafe performans değerleri ile ilişkisi incelenmiştir. Çalışmaya katılan sporcuların somatotip değerleri ortalaması(endomorfmezomorf- ektomorf) sırasıyla 3,66-4,15-2,56 olarak bulunmuştur. Cinsiyet bakımından, kadın yüzücülerin ortalama somatotip değeri 3,48-4,26-2,82 erkek yüzücülerin ise 3,01-4,39-2,89 olarak hesaplanmıştır. Kadın ve erkek sporcuların somatotip yapıları endomorfik mezomorf olarak hesaplanmıştır. Erkek ve kadın sporcularda somatotip yap1 ve performans değerleri benzerlik göstermektedir. Endomorf yapı ile serbest stil ( $\mathrm{r}=242)$, sirtüstü stil $(\mathrm{r}=254)$, kelebek stil $(\mathrm{r}=269)$ ve kurbağalama stil $(\mathrm{r}=400)$ yüzme performansı arasında anlamlı korelasyon tespit edilmiştir. Yaş gruplarına göre Boy $(p=.000)$, Kilo $(p=.000)$, BKİ $(p=.003)$, Serbest stil $(p=.006)$, Kelebek stil $(p=.003)$ ve Kurbağalama stil $(p=.030)$ değerlerinde anlamlı farklılık saptanmıştır. Cinsiyet değişkenine göre kadın ve erkek sporcular arasında somatotip yapı ve performans değerlerinde anlamlı farlılık bulunamamıştır. Sonuç olarak adölesan dönem kadın ve erkek yüzücülerin performans ve somatotip değerleri benzerlik gösterirken yaş artışı ile birlikte kısa mesafe yüzme performansında artış görülmüştür. Endomorf yapı ile yüzme performansı arasında anlamlı ilişki tespit edilmiştir.

Anahtar Kelimeler: Adolesan, Yüzme, Somatotip, Sprint Performans1, Yüzme stili.

\section{Giriş}

Sporcularda somatik özellikler, fiziksel kapasite ve performansı arasındaki ilişki spor bilim adamları için ilgi kaynağı olmuştur. Sporda antrenmanın etkilerini belirlemek için (Duche vd., 1993:467-471); Girold vd., 2006:547-554) veya farkl1 müsabaka seviyelerine sahip sporcular arasında ayrım yapmak için (Ugarkovic vd., 2002:227) çeşitli güç, antropometrik ve vücut kompozisyonu değişkenleri kullanılmıştır. Antropometrik özellikler üzerinde yapılan araştırmalarla, değişik vücut profillerinin hangi branşa uygun olduğu tespit edilmeye çalışılmakta ve yetenek tespiti sürecinde bu profillere uygun sporcuların seçimi yapılmaktadır (Söğüt vd., 2004).

Belirli parametreler yüzmede önemli rol oynarlar. Elin boyutu suda etkili ilerlemede önemli bir belirleyicidir ve ayrıca vücut ağırlığı da suda batmamayı belirleyen önemli bir etkendir (Cicchella vd., 2009:155). Birçok araştırma başarılı yüzücülerin antropometrik özelliklerini ve bu özellikler ile yüzme performansı arasındaki ilişkiyi incelemiştir (Grimston ve Hay 1986:60-68; Klentrou ve Montpetit 1991:13-18; Mazza vd., 1993:15-54; Siders vd.,1993:166; Geladaş vd., 2005:139-144).

Erken dönemde aynı yaştaki bireylerin, vücut tipi, fiziksel uygunluk düzeyleri, motivasyonları, becerileri, öğrenme hızı, geçmiş tecrübeleri ve aile ortamları farklılık göstermektedir (Özer ve Özer 2000). İnsan gelişiminde en hızlı büyüme çocukluk ve ergenlik döneminde görülür. Ergenlik dönemi başlarında hormon salınımındaki artışla birlikte boy uzaması ve ağırlık artışı çok fazla olmaktadır (Haywood, 1986).

Çocukluk döneminde somatotipin belirlenmesi yetenek seçiminde kullanılmasının yanı sıra ilgili branştaki yüklenmelerin antropometrik yap1 ve performans düzeyine etkisinin belirlenmesini açısından son derece önemlidir. Literatürü incelediğimizde birçok çalışmada yüzme branşında sporcuların boy, beden kitle indeksi, ön kol ve el yapıs1 gibi üst ekstremiteye odaklanıldığı görülmektedir (Smith 1978; Sharp vd., 1982; Toussaint ve Beek, 1992; Deschodt vd., 1999; Ölmez vd.,2017). Bu çalışmalardan farklı olarak yüzücülerin yüzme stilleri ve somatotip özelliklerini üzerine yapılacak çalışmalar ile vücut yapısının yüzme performansına etkisi belirlenmesi müsabaka veya etkinliklerdeki gereksinimlerine göre vücut gelişimini erken dönemde geliştirmeye yardımcı 
olacaktır. Literatür incelemesi sonucunda fiziksel özellikler, fiziksel kapasiteler ve yüzme performansı arasındaki ilişkiler hakkındaki veriler, elit yüzücüler de dâhil olmak üzere genç ve yetişkin yüzücülerde son derece sinırlıdır.

Bu çalışmada adölesan dönem yüzme sporcularının, yaş, cinsiyet ve fiziksel özelliklerin yüzme performansına etkisini araştırmak ve somatotip yapı ile dört farklı stil kısa mesafe $(50 \mathrm{~m}$.) sprint performansları arasındaki ilişkinin incelenmesi amaçlanmıştır.

\section{Materyal Metod}

\section{Araştırma grubu}

Çalışmaya 2019 yılında, Ordu ve Giresun il merkezinde farklı kulüplerde aktif spor yapan ve resmi ulusal yarışmalara katılan sağlıklı kadın $(n=36$, yaş $=13.00 \pm 1.29$ yıl $)$ ve erkek $(n=25$, yaş $=13.00 \pm 1.13$ yıl) toplam 61 sporcu alınmıştır. Tüm sporcuların gönüllü katılımları, velilerinin yazılı izin onayları ve Helsinki Deklarasyonu prensiplerine uygun olarak gerçekleştirilmiştir.

\section{Verilerin toplanması}

Çalışmaya katılan sporcuların boy uzunluk ölçümleri 0.01 hassasiyetinde olan stadiometre (Holtain Ltd., UK), vücut ağırlıkları bioempedans vücut analiz cihazı (ioi-353, Jawon Medical, Korea), uzuv uzunluk ve çap ölçümlerinde antropometer (Lafayette Instrument Company), deri kıvrım kalınlıkları için skinfold kaliper ölçüm aleti (Holtain Ltd., UK) ve çevre ölçümleri için çelik metre kullanılmıştır. Sporcuların vücudunun sağ tarafından Üst kol çevre (cm) Maksimal bacak çevre $(\mathrm{cm})$ Femur çap $(\mathrm{cm})$ Humerus çap $(\mathrm{cm})$ Triceps skinfold $(\mathrm{mm})$ Subscapular skinfold $(\mathrm{mm})$ Supraspinale skinfold ( $\mathrm{mm}$ ) Medial calf skinfold $(\mathrm{mm})$ ölçümleri yapılmış ve Heath\&Carter metodu ile somatotip değerleri hesaplanmıştır (Carter and Heath, 1990: 352; Mac Dougall vd., 1991: 142). İki boyutlu somatocart üzerinde somatotip yapının belirlenmesinde; ' $((X-k o o r d i n a t=$ ectomorphy - endomorphy), (Y-koordinat $=2 \times$ mesomorphy - $($ endomorphy + ectomorphy $))^{\prime}$ formülü kullanılmıştır. (Carter, 2003: 13). Sporcuların beden kitle indeksleri (BKİ=vücut ağırllğı/boy ${ }^{2}$ ) formülü ile hesaplanmıştır.

\section{Verilerin Analizi}

Çalışmadan elde edilen veriler SPSS programında normallik testi, tanımlayıcı istatistikleri, Mann Whitney U test, Kruskal Wallis test ve Spierman korelasyon testleri ile değerlendirilmiş ve anlamlılık düzeyi olarak $\mathrm{P}<0,05$ kullanılmıştır.

\section{Bulgular}

Çalışmadan elde edilen verilerin analiz sonuçları aşağıda tablo olarak verilmiştir. 


\begin{tabular}{|c|c|c|c|c|c|}
\hline \multirow{4}{*}{ Yaş } & & & & & \\
\hline & Cinsiyet & $\mathrm{N}$ & Med. \pm Std.dev. & Z & $\mathrm{P}$ \\
\hline & Kadın & 36 & $13.00 \pm 1.29$ & \multirow{2}{*}{-.279} & \multirow{2}{*}{.780} \\
\hline & Erkek & 25 & $13.00 \pm 1.13$ & & \\
\hline \multirow{2}{*}{ Boy } & Kadın & 36 & $152.75 \pm 8.47$ & \multirow{2}{*}{-.763} & \multirow{2}{*}{.446} \\
\hline & Erkek & 25 & $156.00 \pm 9.42$ & & \\
\hline \multirow{2}{*}{ Kilo } & Kadın & 36 & $46.30 \pm 10.21$ & \multirow{2}{*}{-.645} & \multirow{2}{*}{.519} \\
\hline & Erkek & 25 & $48.00 \pm 7.12$ & & \\
\hline \multirow{2}{*}{ BKİ } & Kadın & 36 & $19.00 \pm 2.64$ & \multirow{2}{*}{-.734} & \multirow{2}{*}{.463} \\
\hline & Erkek & 25 & $20.00 \pm 1.80$ & & \\
\hline \multirow{2}{*}{ Endomorf } & Kadın & 36 & $3.48 \pm 1.27$ & \multirow{2}{*}{-.851} & \multirow{2}{*}{.395} \\
\hline & Erkek & 25 & $3.01 \pm 1.32$ & & \\
\hline \multirow{2}{*}{ Mezomorf } & Kadın & 36 & $4.26 \pm 1.70$ & \multirow{2}{*}{-.249} & \multirow{2}{*}{.803} \\
\hline & Erkek & 25 & $4.39 \pm 1.69$ & & \\
\hline \multirow[b]{2}{*}{ Ektomorf } & Kadın & 36 & $2.82 \pm 1.27$ & \multirow{2}{*}{-.191} & \multirow{2}{*}{.849} \\
\hline & Erkek & 25 & $2.89 \pm 1.15$ & & \\
\hline \multirow{2}{*}{ Serbest } & Kadın & 36 & $35.48 \pm 9.36$ & \multirow{2}{*}{-.880} & \multirow{2}{*}{.379} \\
\hline & Erkek & 25 & $34.14 \pm 13.33$ & & \\
\hline \multirow{2}{*}{ Sirtüstü } & Kadın & 36 & $42.09 \pm 13.30$ & \multirow{2}{*}{-.044} & \multirow{2}{*}{.965} \\
\hline & Erkek & 25 & $41.28 \pm 15.37$ & & \\
\hline \multirow{2}{*}{ Kelebek } & Kadın & 36 & $40.57 \pm 18.51$ & \multirow{2}{*}{-.286} & \multirow{2}{*}{.775} \\
\hline & Erkek & 25 & $38.09 \pm 19.47$ & & \\
\hline \multirow{2}{*}{ Kurbağalama } & Kadın & 36 & $47.33 \pm 17.07$ & \multirow{2}{*}{-.521} & \multirow{2}{*}{.603} \\
\hline & Erkek & 25 & $44.69 \pm 19.60$ & & \\
\hline
\end{tabular}

Çalışma grubundaki sporcuların fiziksel özellikleri, somatotip yapıları ve yüzme performans değerlerini cinsiyet değişkenine göre karşılaştırdığımızda kadın ve erkek sporcular arasında istatistiksel olarak anlamlı sonuç bulunamamıştır $(\mathrm{P}>0.05)$, (Tablo 1.)

Tablo 2: Yaş Gruplarına Göre Karşılaştırma Sonuçları

\begin{tabular}{|c|c|c|c|c|}
\hline & Yaş Grupları & $\mathrm{N}$ & Med. \pm Std.dev. & $\mathrm{P}$ \\
\hline \multirow{3}{*}{ Boy } & $10-11$ & 5 & $139.00 \pm 6.76$ & \multirow{3}{*}{$.000 *$} \\
\hline & $12-13$ & 29 & $151.50 \pm 7.58$ & \\
\hline & $14-15$ & 27 & $159.00 \pm 7.35$ & \\
\hline \multirow{3}{*}{ Kilo } & $10-11$ & 5 & $40.60 \pm 4.90$ & \multirow{3}{*}{$.000^{*}$} \\
\hline & $12-13$ & 29 & $44.00 \pm 7.08$ & \\
\hline & $14-15$ & 27 & $50.60 \pm 8.23$ & \\
\hline \multirow{3}{*}{ BKİ } & $10-11$ & 5 & $18.00 \pm 2.21$ & \multirow{3}{*}{$.009 *$} \\
\hline & $12-13$ & 29 & $19.00 \pm 2.26$ & \\
\hline & $14-15$ & 27 & $20.00 \pm 2.08$ & \\
\hline \multirow{3}{*}{ Endomorf } & $10-11$ & 5 & $2.95 \pm 1.28$ & \multirow{3}{*}{.421} \\
\hline & $12-13$ & 29 & $3.27 \pm 1.11$ & \\
\hline & $14-15$ & 27 & $3.73 \pm 1.45$ & \\
\hline \multirow{3}{*}{ Mezomorf } & $10-11$ & 5 & $4.88 \pm 1.96$ & \multirow{3}{*}{.408} \\
\hline & $12-13$ & 29 & $3.98 \pm 1.34$ & \\
\hline & $14-15$ & 27 & $4.58 \pm 1.94$ & \\
\hline \multirow{3}{*}{ Ektomorf } & $10-11$ & 5 & $3.35 \pm 2.20$ & \multirow{3}{*}{.289} \\
\hline & $12-13$ & 29 & $2.93 \pm 1.23$ & \\
\hline & $14-15$ & 27 & $2.80 \pm 0.91$ & \\
\hline \multirow{3}{*}{ Serbest } & $10-11$ & 5 & $40.28 \pm 6.04$ & \multirow{3}{*}{$.006^{*}$} \\
\hline & $12-13$ & 29 & $35.43 \pm 11.81$ & \\
\hline & $14-15$ & 27 & $33.30 \pm 10.87$ & \\
\hline \multirow{2}{*}{ Sirtüstü } & $10-11$ & 5 & $43.60 \pm 5.51$ & \multirow{2}{*}{.130} \\
\hline & $12-13$ & 29 & $42.09 \pm 14.12$ & \\
\hline
\end{tabular}




\begin{tabular}{lcccc}
\hline & $14-15$ & 27 & $40.00 \pm 15.39$ & \\
\hline \multirow{3}{*}{ Kelebek } & $10-11$ & 5 & $55.70 \pm 8.70$ & \multirow{2}{*}{$.003 *$} \\
\cline { 2 - 4 } & $12-13$ & 29 & $41.23 \pm 17.67$ & \\
\cline { 2 - 4 } Kurbağalama & $14-15$ & 27 & $36.11 \pm 21.17$ & \multirow{2}{*}{$.030 *$} \\
\cline { 2 - 4 } & $10-11$ & 5 & $52.73 \pm 4.95$ \\
\cline { 2 - 4 } & $12-13$ & 29 & $45.50 \pm 18.06$ & \\
\hline
\end{tabular}

Çalışmadan elde edilen sonuçlar yaş gruplarına göre değerlendirildiğinde Boy $(\mathrm{p}=0.00)$, Kilo $(p=0.00)$, ve BKİ $(p=0.09)$, Serbest $(p=.006)$, Kelebek $(p=.003)$, ve Kurbağalama $(p=.030)$ değerlerinde istatistiksel olarak anlamlı fark tespit edilmiştir $(\mathrm{P}<0.05)$. Endomorf $(\mathrm{p}=.421)$, Mezomorf $(p=.408)$, Ektomorf $(p=.289)$ ve Sirtüstü $(p=.130)$, değerlerinde anlamlı bir fark bulunmamıştır $(\mathrm{P}>0.05)$, (Tablo 2.)

Tablo 3: Anlamlı Farklılık Tespit Edilen Verilerin Yaş Grubu Değişkenine Göre Karşılaştırma

\begin{tabular}{|c|c|c|c|c|}
\hline & & Yaş Grupları & $\mathrm{Z}$ & $\mathrm{P}$ \\
\hline \multirow{4}{*}{ Boy } & \multirow{2}{*}{$10-11$} & $12-13$ & -2.214 & $.027 *$ \\
\hline & & $14-15$ & -3.271 & $.001 *$ \\
\hline & \multirow{2}{*}{$12-13$} & $10-11$ & -2.214 & $.027 *$ \\
\hline & & $14-15$ & -3.380 & $.001 *$ \\
\hline \multirow{4}{*}{ Kilo } & \multirow{2}{*}{$10-11$} & $12-13$ & -2.188 & $.029 *$ \\
\hline & & $14-15$ & -3.270 & $.001 *$ \\
\hline & \multirow{2}{*}{$12-13$} & $10-11$ & -2.188 & $.029 *$ \\
\hline & & $14-15$ & -3.706 & $.000 *$ \\
\hline \multirow{4}{*}{ BKI } & \multirow{2}{*}{$10-11$} & $12-13$ & -.592 & .554 \\
\hline & & $14-15$ & -2.154 & $.031 *$ \\
\hline & \multirow{2}{*}{$12-13$} & $10-11$ & -.592 & .554 \\
\hline & & $14-15$ & -2.694 & $.007 *$ \\
\hline \multirow{4}{*}{ Serbest } & \multirow{2}{*}{$10-11$} & $12-13$ & -1.532 & .126 \\
\hline & & $14-15$ & -2.258 & $.024 *$ \\
\hline & \multirow{2}{*}{$12-13$} & $10-11$ & -1.532 & .126 \\
\hline & & $14-15$ & -2.591 & $.010 *$ \\
\hline \multirow{4}{*}{ Kelebek } & \multirow{2}{*}{$10-11$} & $12-13$ & -2.067 & $.039 *$ \\
\hline & & $14-15$ & -2.416 & $.016 *$ \\
\hline & \multirow{2}{*}{$12-13$} & $10-11$ & -2.067 & $.039 *$ \\
\hline & & $14-15$ & -2.673 & $.008 *$ \\
\hline \multirow{4}{*}{ Kurbağalama } & \multirow{2}{*}{$10-11$} & $12-13$ & -1.434 & .151 \\
\hline & & $14-15$ & -2.154 & $.031 *$ \\
\hline & \multirow{2}{*}{$12-13$} & $10-11$ & -1.434 & .151 \\
\hline & & $14-15$ & -1.919 & .550 \\
\hline
\end{tabular}

Boy ve kilo ve kelebek değerlerinde tüm yaş grupları arasında istatistiksel olarak anlamlı farkl1lık tespit edilmiştir. BKI ve serbest stil yüzme değerlerinde 14-15 yaş grubundaki sporcular ile 10-11 ve 12-13 yaş grubundaki sporcular arasında istatistiksel olarak anlamlı fark bulunmuştur $(\mathrm{P}<0.05)$. Kurbağalama değerlerinde $10-11$ ile $14-15$ yaş grubundaki sporcular arasında 
istatistiksel anlamlı fark bulunmuştur. ( $\mathrm{P}>0.05)$, (Tablo 3.)

Tablo 4: Somatotip Yapı İle Yüzme Performansı Ve Bazı Değișkenler Arasındaki İlișki

\begin{tabular}{|c|c|c|c|c|c|c|c|c|}
\hline & & Endo & Mezo & Ekto & Serbest & Sirtüstü & Kelebek & Kurb̆ \\
\hline \multirow{2}{*}{ Yaş } & $\mathrm{r}$ & .128 & .023 & -.128 & -.377 & $\begin{array}{l}-.184 \\
\end{array}$ & $\begin{array}{l}.444 \\
\end{array}$ & -.352 \\
\hline & $\mathrm{p}$ & .327 & .863 & .324 & 0.063 & .156 & 0.00 & 0.00 \\
\hline \multirow{2}{*}{ Boy } & $r$ & .135 & -.203 & .054 & -.303 & -.264 & -.414 & -.305 \\
\hline & $\mathrm{p}$ & .298 & .117 & .677 & 0.01 & 0.04 & 0.01 & 0.01 \\
\hline \multirow{2}{*}{ Kilo } & $r$ & .473 & .091 & -.455 & -.299 & -.133 & -.312 & -.158 \\
\hline & $\mathrm{p}$ & 0.00 & .486 & $\mathbf{0 . 0 0}$ & 0.00 & .306 & 0.00 & .225 \\
\hline \multirow{2}{*}{ BKI } & $\mathrm{r}$ & .697 & .426 & -.874 & -.163 & .058 & -.080 & .050 \\
\hline & $\mathrm{P}$ & 0.00 & 0.01 & 0.00 & .210 & .660 & .541 & .700 \\
\hline \multirow{2}{*}{ Endomorf } & $r$ & 1.000 & .333 & -.675 & .242 & 254 & 269 & . 400 \\
\hline & $\mathrm{p}$ & - & 0.09 & 0.00 & 0.06 & 0.04 & 0.03 & 0.00 \\
\hline \multirow{2}{*}{ Mezomorf } & $\mathrm{r}$ & .333 & 1.000 & -.513 & -.016 & .215 & .088 & .100 \\
\hline & $\mathrm{p}$ & 0.009 & - & 0.00 & .901 & 0.96 & .501 & .444 \\
\hline \multirow{2}{*}{ Ektomorf } & $r$ & -.675 & -.513 & 1.000 & .038 & -.168 & -.098 & -.171 \\
\hline & $\mathrm{p}$ & 0.00 & 0.00 & - & .771 & .196 & .453 & .187 \\
\hline
\end{tabular}

Çalışmada elde edilen verilerin korelasyon sonuçlarına göre, yaş değişkeni ile kelebek $(\mathrm{r}=-.444 . \mathrm{p}=0.00)$ ve kurbağalama $(\mathrm{r}=-.352 . \mathrm{p}=0.00)$ yüzme dereceleri arasında orta düzeyde negatif anlamlı ilişki vardır $(\mathrm{P}<0.05)$.

Boy değerleri ile serbest $(r=-.303 . p=0.01)$ ve surtüstü $(r=-.204 . p=0.04)$ yüzme dereceleri arasında orta düzeyde negatif anlamlı ilişki vardır $(\mathrm{P}<0.05)$.

Kilo değerleri ile serbest stil $(\mathrm{r}=-.299 . \mathrm{p}=0.00)$ ve kelebek stil( $(\mathrm{r}=-.312, \mathrm{p}=0.00) \quad$ yüzme değerleri arasında orta düzeyde negatif anlamlı ilişki bulunmuştur $(\mathrm{P}<0.05)$.

BKİ değerleri ile yüzme performansı arasında anlamlı ilişki bulunamamıştır. ( $\mathrm{P}>0.05)$.

Endomorf yap1 ile serbest $(\mathrm{r}=.242, \mathrm{p}=0.06)$, sirtüstü( $\mathrm{r}=.254, \mathrm{p}=0.04)$, kelebek(r=.269, $\mathrm{p}=0.03)$ ve kurbağalama stil $(\mathrm{r}=400, \mathrm{p}=0.00)$ yüzme performans dereceleri arasında pozitif anlamlı ilişki bulunmuştur $(\mathrm{P}<0.05)$.

Mezomorf yapı ile serbest stil( $\mathrm{r}=-.513, \mathrm{p}=0.00)$ yüzme performans derecesi arasında orta düzeyde negatif anlamlı ilişki bulunmuştur $(\mathrm{P}<0.05)$. Mezomorf yapı ile sırtüstüi( $\mathrm{r}=242, \mathrm{p}=0.06)$, kelebek $(\mathrm{r}=-.016, \mathrm{p}=0.90)$, ve kurbağalama $(\mathrm{r}=.088, \mathrm{p}=0.50)$ dereceleri arasında anlamlı ilişki bulunamamıştır $(\mathrm{P}>0.05)$.

Ektomorf yapı ile yüzme performansları arasında düşük düzeyde negatif ilişki bulunmuştur. Korelasyon istatistiksel olarak anlamlı değildir $(\mathrm{P}>0.05)($ Tablo 4$)$.

\section{Tartışma ve Sonuç}

Sporda en önemli hedef başarıya ulaşmaktır. Bir sporcu için başarı ise müsabakada rakiplerini yenmektir. Sporcu ve antrenörlerin bu amaca ulaşması için fiziksel, fizyolojik ve psikolojik olarak en ideal seviyede olması gereklidir. Son yıllarda tüm dünyada olduğu gibi ülkemizde de spor alanındaki bilimsel çalışmalar artmış ve bu çalışmalardan elde edilen veriler sporcuların farklı spor dallarına yönlendirilmesinde, küçük sporcuların eğitiminde ve aynı zamanda elit sporcuların antrenmanlarında performansının artırılmasında büyük önem taşımaktadır. $\mathrm{Bu}$ çalışmada incelenen yüzme performansı ve somatotip özelliklerin karşılaştırıldığı veya aralarındaki ilişkiyi birlikte değerlendiren ulusal ve uluslararası literatürde oldukça kısıtlı çalışma olduğu 
görülmüş̧ür. Bu konularla ilgili birbirinden bağımsız çalışmalara rastlandı ve yapılan bu araştırma, literatürdeki diğer bulgularla desteklenmeye çalış1ldı.

Çalışmamızda sporcuların somatotip ortalama değerleri 3,66-4,15-2,56 olarak bulunmuştur. Cinsiyet bakımından incelediğimizde kadın yüzücülerin ortalama değeri 3,48-4,26-2,82 erkek yüzücülerde ise 3,01-4,39-2,89 olarak hesaplanmıştır. Kadın ve erkek sporcuların somatotip yapıları endomorfik mezomorf olduğu tespit edilmiştir.

Ayan ve Kavi (2016:23) 8-14 yaş arası kadın yüzücülerin somatotip yapılarını incelediği çalışmasında kadın yüzücülerin 3,70-4,30-2,20 değerlerine sahip olduğunu ve endomorfik mezomorf yapıda olduğunu bildirmiş̧ir. Ventrella vd. (2008:383) 6-11 yaşarası İtalyan ve Estonyalı çocukların somatotip yapılarının incelenmesi konulu çalışmalarında, İtalyan kadınların somatotip değerlerini 4,40-3,60-2,30 olarak bulmuşlardır. Estonyalı kadınların somatotip değerlerini ise 3,80-4,20-2,80 olarak bulmuşlardır. Bostancı vd. (2017:12-21) 12-13 yaş yüzücülerin antropometrik özelliklerini incelediği çalışmada kadın sporcularda 3,29-3,84-3,05, erkek sporcularda 2,98-4,16-3,21 somatotip değerler bildirmiş̧ir. Hınçal ve Gültekin (2018:37-51) 9-13 yaş grubundaki kadın yüzücülerde 3,502,80-2,70, erkek yüzücülerde 2,50-3,50-3,20, 14-19 yaş grubundaki kadın yüzücülerde 3,60-2,702,40, erkek yüzücülerde 2,70-3,10-3,10 ortalama değerler bildirmiştir. Çalışmamızda kadın ve erkek sporculara ait somatotip yapı ile literatür verileri büyük oranda benzerlik göstermektedir. Çalışma sonuçlarından farklı olarak Hınçal ve Gültekin (2018:37) erkek yüzücülerin somatotip değerleri mezomorfik ektomorf olduğu bildirilmiştir. Bir diğer çalışmada Fernandez vd. (2002:67-79) elit yüzücülerin kinantropometrik özelliklerinin ve yüzme performansı için önemlerinin uzmanlaşmış literatüre dayanan bir bibliyografik incelemesinde, elit erkek yüzücüler ektomorf-endomorf, elit kadın yüzücülerin ise merkezi veya dengeli mezomorf yapıda olduğunu bildirmiştir. Bunun yanında yüzücülerin diğer sporculara göre daha yüksek vücut kütle yüzdesine sahip olduğunu, bu durumun vücutlarına olumlu yönde etkileyebileceğini bildirmiştir. Yüzme sporcularındaki somatotip yapı farkl1lı̆̆ını sporcunun yaşı, spor yaşı, antrenman programı ve özellikle performans düzeyi gibi farklılıklardan kaynaklandı̆̆ını söyleyebiliriz.

Sporcuların yüzme performansı ve somatotip yapılarını cinsiyet bakımından karşılaştırdığımızda kadın ve erkek sporcular arasında anlamlı farklılık bulunamamıştır. Yüzme performansları bakımından dört farklı yüzme stilinde de erkek sporcuların daha iyi derecelere sahip oldukları gözlenirken, somatotip yapı özelliklerinde erkek sporcuların mezomorfi ve ektomorfi değerleri kadın sporculardan daha yüksek, endomorfi değerleri daha düşük bulunmuştur.

Mazza vd. (1993:15) 1991 Dünya Şampiyonası'ndaki en iyi 12 yüzücünün antropometrik özelliklerini diğer rakiplerle karşılaştırmış ve serbest stil erkek yüzücülerin daha uzun üst ve alt ekstremiteye sahip olduğu sonucuna varırken, benzer şekilde kadın sporcularda karşılaştırıldığında alt ekstremite uzunlukları ile bilioskristal ve bilek genişliklerinin düşük zaman performansına sahip yüzücülerden daha büyük olduğunu bildirmiştir.

Çağlayan ve Yanar (2017:1-5) erkek ve kadın yüzücülerde vücut kompozisyonlarını değerlendirmiş ve kadın sporcularda deri kıvrım kalınlığının, erkek sporcularda ise boy, kilo ve BKİ değerlerinin daha yüksek olduğunu bu sonucun anatomik yapı ve fiziksel gelişim farklılığından kaynaklandığını bildirmiştir. Zampagni ve ark (2008:1298) elit kadın ve erkek yüzücülerde yaptığı çalışmada serbest stil 50 metre performansında cinsiyetler arasında fark olmadı̆̆ını, fakat $100,200,400$ ve 800 metre de anlamlı fark olduğunu bildirmiştir. Literatürdeki farklı sonuçların bu yaş grubundaki sporcuların ergenlik dönemindeki cinsiyete bağlı gelişim dönemi olması nedeniyle yetişkin sporcularda ise anatomik farklılıklardan kaynaklandığını söyleyebiliriz.

Çalışma bulgularını yaş gruplarına göre değerlendirdiğimizde Boy, kilo, BKİ, Serbest stil, kelebek stil ve Kurbağalama stil değerlerinde anlamlı farklılık bulunmuştur. Bu değişkenlerin çoklu karşılaştırma sonuçlarına göre boy ve kilo değerlerinde tüm yaş grupları arasında anlamlı fark bulunurken BKİ değerlerinde, 14-15 yaş grubu ile 10-11 ve 12-13 yaş grubu arasında anlamlı 
bulunmuştur. Bu sonuçlar yaş faktörünün bu dönemde fiziksel özellikler üzerinde belirleyici etkiye sahip olduğunu göstermektedir. Benzer şekilde, yüzme performansında serbest stilde 14-15 yaş grubunun diğer yaş gruplarından anlamlı derecede iyi olduğunu, kelebek stilde tüm yaş grupları arasında, kurbağalama stilde ise 14-15 yaş grubunun 10-11 grubundan daha iyi derecelere sahip olduğu görülmüştür.

Nigam (2010:10) 19 yaş altı Hindistan milli takım yüzücülerinde farklı yüzme stilleri veya etkinliklerde yüzücülerin vücut boyutlarında ve formlarında erken yaşlarda farklıl1klar olduğu bildirmiştir. Benzer bir çalışmada Gontarev vd., (2016:160) genç erkek Makedon futbol oyuncularında 14-18 yaş gruplarında somatotip yapıyı incelemiş 14,15,16 yaş gruplarında mezomorf ektomorf 17,18 yaş grubundaki futbolcuların ise mezomorf yapıya sahip olduklarını bildirmiştir. Bu sonuçlar bizim çalışmadan elde edilen bulgularla benzerlik göstermektedir. Sonuç olarak yaş artışı ile birlikte fiziksel gelişim ve yüzme performansı doğru orantılı olarak artmaktadır.

Çalışmada elde edilen korelasyon sonuçlarına göre; yaş değişkeni ile kelebek ve kurbağalama stil yüzme derecesi arasında negatif yönlü orta düzeyde anlamlı ilişki bulunmuştur. Benzer şekilde boy uzunluğu ile her dört stil yüzme dereceleri arasında ve kilo ile kelebek ve serbest stil yüzme dereceleri arasında negatif yönlü orta düzeyde anlamı ilişki tespit edilmiştir. Bu sonuçlara göre yaş, boy ve kilo artışı $50 \mathrm{~m}$. yüzme sürelerinde anlamlı düşüşe neden olmakta ve dolayısı ile yüzme performansına olumlu katkı sağlamaktadır. Çalışma sonucundaki somatotip yapı ile yüzme performansı arasında endomorf değerleri ile dört stil yüzme performansı arasında pozitif yönlü orta düzeyde anlamlı ilişki vardır. Mezomorf değerleri ile sırtüstü, Kelebek ve Kurbağalama stil yüzme derecesi arasında pozitif düşük korelasyon vardır. Ektomorf değeri ile Sırtüstü, Kelebek ve Kurbağalama stil yüzme dereceleri arasında negatif düşük düzeyde korelasyon tespit edilmiştir.

Nigam (2010:10) 19 yaş altı Hindistan milli takım yüzücülerinde Yüzme performansı ile boy, kilo, göğüs çevresi, kol açıklığı, kol uzunluğu, endomorfi, mezomorfi, ektomorfi ve yağ yüzdesi gibi somatometrik değişkenler arasında anlamlı korelasyonlar olduğunu bildirmiştir.

Ölmez vd. (2017:95) yüzücülerin 50 m serbest stil yüzme performansları ile kulaç ve kol uzunlukları arasında zıt yönde ve orta düzeyde; omuz genişlikleri ile arasında ise zıt yönde ve düşük düzeyde bir ilişki olduğunu bildirmiştir. Sonuç olarak yüzücülerin kulaç ve kol uzunluğu ile omuz genişliği değerleri arttıkça $50 \mathrm{~m}$ serbest stil yüzme sürelerinin kısalacağını göstermektedir.

Geladaş vd. (2005:139)12-14 yaş erkek yüzücülerde $100 \mathrm{~m}$ serbest stil performansı ile tüm değişkenler arasında korelasyon olduğunu ve $100 \mathrm{~m}$ serbest stil performansının anlamlı yordayıcıları olarak üst ekstremite uzunluğu, yatay atlama ve kavrama kuvveti saptanmıştır. Kadınlarda vücut yüksekliği, üst ekstremite ve el uzunluğu, omuz esnekliği ve yatay atlama ile $100 \mathrm{~m}$ serbest stil dereceleri anlamlı derecede ilişkili olduğunu bildirmiştir.

$\mathrm{Bu}$ sonuçlardan farklı olarak Güler (2000) 9-18 yaş grubu yüzücülerde antropometrik özellikler ile performans arasındaki ilişkiyi incelemiş ve antropometrik değerler ile yüzme performansı arasında önemli bir ilişki olmadığını, puberte öncesi yüzücülerde, fiziksel boyutlar, vücut şekli ve esneklikle ilgili olarak performansı iyi yönde etkileyecek belirleyici bir ilişki bulunmadığını bildirmiştir.

Sonuç olarak çalışma verileri ve literatürden elde edilen bilgiler ışığında genç yüzücülerde kısa mesafe yüzme performansı antropometrik özellikler ile kısmen açıklanabilmektedir. Performans düzeyini, spor yaşı, antrenman seviyesi ve yüzme tekniği gibi parametrelerin yanı sıra antropometrik özellikler ve fiziksel kapasite de etkilemektedir.

Yüzme performansındaki farklılıklarının sporcuların büyüme ve gelişme dönemine ait yapısal özellikleri, sporculuk yaşları ve antrenman düzeyinden kaynaklandığı düşünülmektedir. Kadın sporcular ile erkek sporcuların yaş ortalamalarının yakın olması somatotip yapılarının ve performans değerlerinin birbirine yakın olmasını ortaya çıkarmıştır. Bu konuda kesin bir sonuca 
ulaşmak için yaş grupları (yetişkin, master vb.)ve performans düzeyini(Kulüp, Milli takım )farklı gruplar arasında daha fazla araştırma sonuçlarına ihtiyaç vardır.

\section{Kaynakça}

Ayan V, Kavi N. (2016). 8-14 Yaş Arası Kız Yüzücülerin Somatotip Yapılarının ve Yatay Sıçrama Özelliğinin İncelenmesi. Int. Journal of Science Culture and Sport (IntJSCS), 4(1):23-30. https://doi.org/10.14486/IntJSCS510

Bostanc1, Ö., Ateş, A., Yılmaz, A. K., \& Kabadayı, M. (2017). 12-13 Yaş Yüzücülerin Cinsiyetlerine Göre Antropometrik Özelliklerinin Karş1laştırılması. İnönü Üniversitesi Beden Eğitimi Ve Spor Bilimleri Dergisi, 4(3), 12-21. https://doi.org/10.1501/sporm_0000000236.

Carter J.E.L, Heath BH. (1990). Somatotyping Development and Applications. 1.Edition, Newyork: Cambridge University Pres, 352-367.

Carter, J.E.L (2003). The Heath-Carter antropometric somatotype. Instruction manual-Department of Exercise and Nutritional Sciences San Diego State University. CA. USA.

Cicchella A, Jidong L, Jürimäe T, Zini M, Passariello C, Rizzo L, Stefanelli C, (2009). Anthropometric comparison between young Estonian and Chinese swimmers.Journal of human sport and exercise. 4(2) 154-160. https://doi.org/10.4100/jhse.2009.42.08

Çağlayan, A., Yanar, Ş. (2017) Erkek ve Kadın Yüzücülerin Vücut Kompozisyonlarının Karşılaştırılması. Kilis 7 Aralık Üni. Beden Eğitimi ve Spor Bilimleri Dergisi, 1(2),1- 5. https://doi.org/10.1501/sporm_0000000172

Deschodt, VJ, Arsac, LM, and Rouard, AH. (1999). Relative contribution of arms and legs in humans to propulsion in 25-m sprint front-crawl swimming. European journal of applied physiology and occupational physiology 80: 192-199. https://doi.org/10.1007/s004210050581

Duche, P, Falgairette, G, Bedu, M, Lac, G, Robert, A, and Coudert, J.( 1993) Analysis of performance of prepubertal swimmers assessed from anthropometric and bio-energetic characteristics. Eur J Appl PhysiolOccup Physiol 66: 467-471. https://doi.org/10.1007/bf00599623

Fernandes, R., Barbosa, T., \& Vilas-Boas, J. P. (2002). Determinant kinantropometric factors in swimming. Brazilian journal of kinanthropometry and human performance, 4(1), 67-79. https://doi.org/10.1249/00005768-198602000-00011

Grimston S., Hay J.(1986) Relationships among anthropometric and stroking characteristics of college swimmers. Med. Science Sports Exerc. (18) 60-68. https://doi.org/10.1249/00005768-198602000-00011

Geladas, N. D., Nassis, G. P., \& Pavlicevic, S. (2005). Somatic and physical traits affecting sprint swimming performance in young swimmers. International Journal of Sports Medicine, 26(02), 139-144. https://doi.org/10.1055/s-2004-817862

Girold, S, Calmels, P, Maurin, D, Milhau, N, and Chatard, JC. (2006) Assisted and resisted sprint training in swimming. J. Strength Cond Research 20: 547-554. https://doi.org/10.1519/r16754.1

Gontarev, S., Kalac, R., Zivkovic, V., Ameti, V., \& Redjepi, A. (2016). Anthropometrical Characteristics andSomatotype of Young Macedonian Soccer Players. International Journal of Morphology, 2016;34(1):160-167. https://doi.org/10.4067/s0717-95022016000100024

Güler, Ç. G. (2000). 9-18 yaş grubu müsabık yüzücülerde eklem hareket genişliğinin ve atropometrik parametrelerin yüzme performansi ile ilişkisi ve bunu temel alan yeni bir esneklik 
programının düzenlenmesi. Yayımlanmamış yüksek lisans tezi, Sağlık bilimleri Enstitüsü, Marmara üniversitesi, İstanbul. https://doi.org/10.33631/duzcesbed.397362

Haywood, K.,M. (1986). Life Span Motor Development.Champaign. Human Kinetics Pub. Inc

Hınçal, S. H., \& Gültekin, T. (2018). Elit Yüzücülerde Antropometrik-Somatotip Değişkenler ve Somatotipin Performansa Etkisi. SPORMETRE Beden Eğitimi ve Spor Bilimleri Dergisi, 16(4), 37-51. https://doi.org/10.1501/sporm_0000000233

Klentrou P., Montpetit R. (1991) Physiologic and physical correlates of swimming performance. Journal Swimming Res.; 7), 13-18

MacDougall, J. D., Wenger, H. A., \& Green, H. J. (1991). Physiological testing of the highperformance athlete Champaign, Ill.: Human Kinetics Books. 141-147.

Mazza, J. C., Ackland, T., Bach, T., \& Cosolito, P. (1994). Absolute body size. In Kinanthropometry in aquatic sports. Human Kinetics Publishers. 15-54.

Nigam, S. (2010). Relationship between different swimming styles and somatotype in national level swimmers. British Journal of Sports Medicine, (44):10-13. https://doi.org/10.1136/bjsm.2010.078725.40

Ölmez, C., Yüksek, S., Üçüncü, M., \& Ayan, V. (2017). 8-12 yaş çocuklarda bazı antropometrik özellikler ile 50 metre serbest stil yüzme performansı arasındaki ilişkinin incelenmesi. Turkiye Klinikleri Journal of Sports Sciences, 9(3), 95-100. https://doi.org/10.5336/sportsci.2016-54026

Özer, K. M., \& Özer, D. S. (2000). Çocuklarda Motor Gelişim, Kazanc1 Kitap Tic. A.Ş., 230, İstanbul.

Sharp, RL, Troup, JP, and Costill, DL. (1982). Relationship between power and sprint freestyle swimming. Med. Science Sports Exercise 14: 53-56. https://doi.org/10.1249/00005768198214010-00010

Siders W, Lukaski H, Bolonchuk W( 1993). Relationships among swimming performance, body composition and somatotype in competitive collegiate swimmers. J. Sports Med. Phys Fitness. 33(2) 166-171.

Smith, L. (1978). Anthropometric measurements, and arm and leg speed performance of male and female swimmers as predictors of swim speed. J Sports Med Phys Fitness 18: 153-168.

Söğüt, M., Müniroğlu, R. S., Deliceoğlu, G. (2004). Farklı Kategorilerdeki Genç Erkek Tenis Oyuncularının Antropometrik Ve Somatotip Özelliklerinin İncelenmesi. Spormetre Beden Ë̆t. ve Spor Bilimleri Dergisi, 2(4), 155-162. https://doi.org/10.1501/sporm_0000000040

Toussaint, HM and Beek, PJ. (1992) Biomechanics of competitive front crawl swimming. Sports Med. 13: 8-24. https://doi.org/10.2165/00007256-199213010-00002

Ugarkovic, D, Matavulj, D, Kukolj, M, and Jaric, S.( 2002) Standard anthropometric, body composition, and strength variables as predictors of jumping performance in elite junior athletes. Journal of Strength \& Conditioning Research, 16: 227-230. https://doi.org/10.1519/1533-4287(2002)016<0227:sabcas $>2.0 . c 0 ; 2$

Ventrella A, Semproli S, Jürimäe J, Toselli S, Claessens A, Jürimäe T, Brasili P. (2008). Somatotype in 6-11-year-old Italian and Estonian schoolchildren. HOMO-Journal of Comparative Human Biology, 59(5): 383-396. https://doi.org/10.1016/j.jchb.2007.07.001

Zampagni, M. L., Casino, D., Benelli, P., Visani, A., Marcacci, M., \& De Vito, G. (2008). Anthropometric and strength variables to predict freestyle performance times in elite master 
swimmers. Journal of Strength \& Conditioning Research,22(4), 1298-1307. https://doi.org/10.1519/jsc.0b013e31816a597b. 